OPEN ACCESS

Edited by:

Lavinia Alberi,

University of Fribourg, Switzerland

Reviewed by:

Elizabeth M. Powell,

University of Maryland, USA

Shilpa D. Kadam,

Johns Hopkins University School

of Medicine and Kennedy Krieger

Institute, USA

*Correspondence:

Claudio Rivera

claudio.rivera@helsinki.fi

Received: 26 July 2015 Accepted: 28 September 2015 Published: 23 October 2015

Citation:

Kourdougli N, Varpula S, Chazal G and Rivera C (2015) Detrimental effect of post Status Epilepticus treatment with ROCK inhibitor Y-27632 in a pilocarpine model of temporal lobe epilepsy.

Front. Cell. Neurosci. 9:413. doi: 10.3389/fncel.2015.00413

\section{Detrimental effect of post Status Epilepticus treatment with ROCK inhibitor Y-27632 in a pilocarpine model of temporal lobe epilepsy}

\author{
Nazim Kourdougli ${ }^{1,2}$, Saara Varpula ${ }^{1,2,3}$, Genevieve Chazal ${ }^{1,2}$ and Claudio Rivera ${ }^{1,2,3 *}$ \\ ${ }^{1}$ INSERM Unité 901, INMED, Marseille, France, ${ }^{2}$ Aix-Marseille Université, UMR S901, Marseille, France, ${ }^{3}$ Neuroscience \\ Center, University of Helsinki, Helsinki, Finland
}

Temporal lobe epilepsy (TLE) is the most common type of epilepsy in adults where $20-30 \%$ of the patients are refractory to currently available anti-epileptic drugs. The RhoA/Rho-kinase signaling pathway activation has been involved in inflammatory responses, neurite outgrowth and neuronal death under pathological conditions such as epileptic insults. Acute preventive administration of ROCK inhibitor has been reported to have beneficial outcomes in Status Epilepticus (SE) epilepsy. In the present study, we evaluate the effect of chronic post SE treatment with the ROCK inhibitor Y-27632 in a rat pilocarpine model of TLE. We used chronic i.p. injections of Y-27632 for 5 days in 6 week old control rats or rats subjected to pilocarpine treatment as a model of TLE. Surprisingly, our findings demonstrate that a systemic administration of Y-27632 in pilocarpinetreated rats increases neuronal death in the CA3 region and ectopic recurrent mossy fiber sprouting (rMFS) in the dentate gyrus of the hippocampal formation. Interestingly, we found that chronic treatment with Y-27632 exacerbates the down-regulation and pathological distribution of the $\mathrm{K}^{+}-\mathrm{Cl}^{-}$cotransporter $\mathrm{KCC} 2$, thus providing a putative mechanism for post SE induced neuronal death. The involvement of astrogliosis in this mechanism appears to be intricate as ROCK inhibition reduces reactive astrogliosis in pilocarpine rats. Conversely, in control rats, chronic Y-27632 treatment increases astrogliosis. Together, our findings suggest that Y-27632 has a detrimental effect when chronically used post SE in a rat pilocarpine model of TLE.

Keywords: temporal lobe epilepsy, ROCK inhibitor, epileptogenesis, astrogliosis, KCC2, mossy fiber sprouting

\section{INTRODUCTION}

Temporal lobe epilepsy (TLE) is the most common type of epilepsy in adults where $20-30 \%$ of the patients are refractory to currently available anti-epileptic drugs (Leonardi and Ustun, 2002; Engel et al., 2012). After an initial insult, both in humans and animal models, TLE is characterized by a clinically quiescent period followed by the occurrence of spontaneous and recurrent seizures (Cavalheiro et al., 1991; Dudek and Sutula, 2007; Curia et al., 2008). The limbic system and, in particular, the hippocampus is one of the major seizure generation loci (McNamara, 1994; Toyoda et al., 2013). During epileptogenesis, the hippocampus displays substantial morphological and functional reorganizations such as excitotoxicity-mediated cell death (Turski et al., 1983; Curia et al., 2008; Bernhardt et al., 2013), reactive gliosis 
(do Nascimento et al., 2012; Rossi et al., 2013; Hadera et al., 2015) and subsequent ectopic recurrent mossy fiber sprouting (rMFS; Tauck and Nadler, 1985; Represa et al., 1989; Sutula et al., 1989; Mathern et al., 1999; Gabriel et al., 2004; de Lanerolle et al., 2012; Peret et al., 2014) as well as GABAergic network rewiring (Sloviter, 1987; Cossart et al., 2005). The signaling pathways and underlying cellular and molecular mechanisms involved in this reactive plasticity are of particular importance since they create a powerful hyperexcitable cerebral focus that drives recurrent disabling seizures (McNamara, 1994; Morimoto et al., 2004; Sloviter, 2008; Jefferys, 2010; Paz and Huguenard, 2015).

The RhoA/Rho-kinase (Rho-ROCK) signaling pathway is highly activated under pathological conditions such as spinal cord injury, ischemia and post-traumatic epilepsy (Fournier et al., 2003; Dubreuil et al., 2006; Ding et al., 2010). Recently, the Rho-ROCK pathways have been involved in numerous neuronal functions such as microglial and astroglial inflammatory responses, neurite outgrowth and neuronal survival within the central nervous system (for review, see Kubo et al., 2008; Fujita and Yamashita, 2014; Hensel et al., 2015). For instance, chronic treatment using ROCK inhibitors such as fasudil or Y-27632 improved recovery after spinal cord injury (Fournier et al., 2003; Boomkamp et al., 2012; Joshi et al., 2015). Also, acute treatment with fasudil or Y-27632 promotes neuronal survival and restrains inflammatory responses in models of ischemia and epilepsy when used prior to insult both in vitro and in vivo (Yamashita et al., 2007; İnan and Büyükafșar, 2008; Ding et al., 2010; Gisselsson et al., 2010).

Under pathophysiological conditions, $\mathrm{GABA}_{\mathrm{A}}$-mediated responses become depolarizing (for review, see Medina et al., 2014). This is believed to participate in epileptogenic processes. This includes the deregulation of functional expression of the neuronal specific $\mathrm{K}^{+}-\mathrm{Cl}^{-}$co-transporter (KCC2) as reported in resected tissues from human TLE patients (Palma et al., 2006; Huberfeld et al., 2007; Muñoz et al., 2007) and animal models of TLE (Pathak et al., 2007; Bragin et al., 2009; Barmashenko et al., 2011) as well as following stroke or traumatic brain injury (Bonislawski et al., 2007; Jaenisch et al., 2010). In addition, recent findings show that human mutations altering KCC2 expression levels have been linked to epilepsy of infancy or iodiopathic epilepsy (Kahle et al., 2014; Puskarjov et al., 2014; Stödberg et al., 2015). Both $\mathrm{GABA}_{\mathrm{A}^{-}}$ mediated depolarization and KCC2 downregulation could participate in post-traumatic processes leading to neuronal death (Shulga et al., 2008, 2012; Pellegrino et al., 2011; Medina et al., 2014; Winkelmann et al., 2015). We have also previously shown that depolarizing GABAergic transmission triggers the activation of the Rho-ROCK signaling pathway, in an acute injury model (Shulga et al., 2012). Considering the involvement of the Rho-ROCK pathway in the pathogenesis of several insults, ROCK seems to be a promising therapeutic target for TLE. However, the effect of ROCK inhibitor treatment during the early time window following Status Epilepticus $(S E)$ has not been investigated. In the present study, we tested the effect of chronic treatment using the ROCK inhibitor Y-27632, a relatively specific inhibitor at low concentrations
(Davies et al., 2000), during the early epileptogenesis period following SE in a rat pilocarpine model of TLE. We found that chronic treatment using the Y-27632 for 5 days post SE exacerbates the neuronal damage and increases early ectopic rMFS within the hippocampus during early epileptogenesis. Moreover, we show that this was accompanied by a downregulation of $\mathrm{KCC} 2$, a major regulator of chloride homeostasis. In conclusion, our findings demonstrate that Y-27632 exacerbates typical features of epileptogenesis which suggest that the ROCK inhibition may not be suitable as an anti-epileptic prophylactic drug in a rodent model of TLE.

\section{MATERIALS AND METHODS}

\section{Animals}

All experiments were approved by the Institut National de la Santé et de la Recherche Médicale (INSERM), by the local ethic committee (project number 66-15112012) and the European community council directive (2010/63/UE). Adult male Wistar rats (Charles River and Janvier Laboratories) had ad libitum access to food and water and were single housed at $22-24^{\circ} \mathrm{C}$ under a $12 \mathrm{~h}$ light/dark cycle.

\section{Rat Model of Temporal Lobe Epilepsy}

Six week old male rats were treated with pilocarpine hydrochloride (360 mg/kg, i.p.; Sigma-Aldrich) $30 \mathrm{~min}$ after scopolamine methyl nitrate $(0.5 \mathrm{mg} / \mathrm{kg}$, i.p.; Sigma-Aldrich). This pilocarpine dose was chosen because it elicited the most severe seizures with limited mortality, as previously described by other investigators (Esclapez et al., 1999; Artinian et al., 2011). Animals were continuously observed to identify the onset of SE. Pilocarpine injections resulted in continuous, repetitive behavioral seizures (defined as SE). Behavioral rating of seizures used the Racine scale (Racine, 1972). Stage 1 was characterized by behavioral arrest; stage 2 by head nodding, gnawing, and mild tremors; stage 3 by unilateral forelimb clonus; stage 4 by bilateral forelimb clonus and stage 5 by severe seizures with prolonged loss of postural control or prolonged tonus. The onset of SE was defined as the time when animals experienced continuous stage 5 seizures. Rats that did not fulfill these criteria for SE were not included in analyses (Table 1). After $3 \mathrm{~h}$ of SE, convulsions were suppressed with diazepam ( $8 \mathrm{mg} / \mathrm{kg}$, i.p.; Roche) and saline solution $(0.9 \% \mathrm{NaCl}$; Sigma-Aldrich) was administrated subcutaneously for re-hydratation of the animals. The injection of diazepam was repeated as needed to help terminate behavioral seizures up to $12 \mathrm{~h}$ after the end of SE. In the present study, only male rats were subjected to pilocarpine injections, since female rats are resistant to pilocarpine (Persinger et al., 1988; Mejías-Aponte et al., 2002; Scharfman and MacLusky, 2014). The variation of sex hormones is a source of variability as testoterone and estradiol modulate seizure activity in both animal models and human patients (Edwards et al., 1999; Smith et al., 1999, 2002; Valente et al., 2002; Galanopoulou et al., 2003; Scharfman et al., 2005; Scharfman and MacLusky, 2006; Giorgi et al., 2014; D'Amour et al., 2015) as well as behavioral cognitive functions in mice model of TLE (Oliveira et al., 2015). Moreover, few studies 
TABLE 1 | Details of animals for pilocarpine induction.

\begin{tabular}{lccc}
\hline & Pilo + Vehicle & Pilo + ROCK-I & P value \\
\hline Number of animals & 16 & 24 & - \\
Age (days) & $40.42 \pm 0.68$ & $39.45 \pm 0.95$ & 0.375 \\
Weight (grams) & $192.42 \pm 6.91$ & $196.63 \pm 3.53$ & 0.78 \\
Global success rate* & $67 \%$ & - & \\
\hline
\end{tabular}

All values are mean \pm SEM; Mann-Whitney test was used for significance. *To avoid variability each Pilo + Veh and Pilo + ROCK-I pair was taken from the same induction session. The number of animals stated here represents $67 \%$ of the animals that successfully went into SE. The original number of rats subjected to pilocarpine was $n=47$ animals.

have reported that KCC2 expression is sexually dimorphic and controlled by estrogen levels (Galanopoulou and Moshé, 2003; Nakamura et al., 2004; Perrot-Sinal et al., 2007; Galanopoulou, 2008; Giorgi et al., 2014) and that ovarian cycle induces changes in $\mathrm{GABA}_{\mathrm{A}}$-receptor subunits and subsequent inhibition (Stell et al., 2003; Maguire et al., 2005; Maguire and Mody, 2007). Thus, these phenomenon could alter the response to drug affecting the GABAergic system under epileptic conditions (Scharfman and MacLusky, 2014).

\section{ROCK Inhibitor Y-27632 Treatment}

Y-27632 (Y0503, Sigma-Aldrich) was dissolved in $0.9 \% \mathrm{NaCl}$ and injected intraperitoneally two times per day at a dose of $10 \mathrm{mg} / \mathrm{kg}$ in a volume of $0.1 \mathrm{ml}$ per $100 \mathrm{~g}$ of body weight. Pilocarpine animals injected with Y-27632 were treated from the 1 st day to the 5 th day post SE. Pilocarpine-treated vehicle animals received a volume of saline solution $(0.1 \mathrm{ml}$ per $100 \mathrm{~g}$ of body weight). The saline or ROCK inhibitor Y-27632 treatment was administrated from $8-24 \mathrm{~h}$ after the last injection of diazepam (8-24 h after termination of behavioral seizures). Age, weight and strain matching control animals were injected intraperitoneally, two times per day, during 5 days with saline $(0.9 \% \mathrm{NaCl})$ or $\mathrm{Y}$ 27632 at a dose of $10 \mathrm{mg} / \mathrm{kg}$ in a volume of $0.1 \mathrm{ml}$ per $100 \mathrm{~g}$ of body weight, and received the same total number of injection than pilocarpine-treated rats.

\section{Immunohistochemstry}

Rats were anesthetized with isoflurane prior to the i.p. injection of $40 \mathrm{mg} / \mathrm{kg}$ of pentobarbital and transcardiacally perfused with cold phosphate buffer saline (PBS, $1 \mathrm{M}$ ) prior to cold $4 \%$ paraformaldehyde in PBS. Brains were post-fixed overnight in $4 \%$ paraformaldehyde in PBS at $4^{\circ} \mathrm{C}$ and then coronally cut with a Leica VT1200S Vibratome (60 $\mu \mathrm{m}$ thick-sections). Sections were then permeabilized and blocked in PBS with $0.3 \%$ Triton X-100 and 5\% normal goat serum (NGS) for $1 \mathrm{~h}$ at room temperature. Incubation with primary antibodies diluted in PBS with 5\% NGS and $0.1 \%$ Triton X-100 was carried out at $4^{\circ} \mathrm{C}$ overnight using rabbit-KCC2 (home product, Ludwig et al., 2003; 1/4000), mouse-SPO (Synaptoporin, Synaptic Systems, 1/800), mouse-NeuN (Millipore, 1/1000) and rabbitGFAP (Sigma, 1/1000). After rinsing three times in PBS, slices were incubated with the corresponding Alexa Fluor-conjugated secondary antibodies diluted in PBS (1/1000, Invitrogen) for $1 \mathrm{~h}$
TABLE 2 | Details of animals, sections and ROIs used for the study.

\begin{tabular}{lcccc}
\hline & Pilo + Veh & Pilo + ROCK-I & Ctrl + Veh & Ctrl + ROCK-I \\
\hline $\begin{array}{l}\text { Number of animals } \\
\begin{array}{l}\text { Number of section } \\
\text { per animal }\end{array}\end{array}$ & 5 & 24 & 12 & 16 \\
$\begin{array}{l}\text { Number of ROls } \\
\text { per animal } \\
\text { (for KCC2 plot } \\
\text { profile analysis) }\end{array}$ & 50 & 50 & 50 & 50 \\
\hline
\end{tabular}

at room temperature and finally counterstained for $5 \mathrm{~min}$ with Hoechst 33258 (10 $\mu \mathrm{g} / \mathrm{ml}$ in PBS, Sigma-Aldrich). Sections were then mounted onto Superfrost Plus glass slides in Fluoromount $\mathrm{G}$ mounting medium or Permount medium for Fluorojade-B protocol. For each section, images were taken using a $10 \times$ or $20 \times$ objective using the same microscope (Axioplan2, Zeiss) and camera (AxiocanMRm, Zeiss) settings. Fluorojade-B staining protocol has been performed following Schmued and Hopkins (2000).

\section{Quantification}

KCC2 analysis was performed in blind. In control vehicleand Y-27632-treated, pilocarpine vehicle- and Y-27632-treated rats, intensity and distribution analyses of KCC2 fluorescence, associated with the membrane or cytosolic regions, were performed on $50 \mathrm{CA} 3$ pyramidal cells randomly selected for each animal condition (Table 2). On each cell, we applied the same straight line from the nucleus to the external cell compartment. The plot profile values were obtained using Plot analysis from Fiji software and the mean \pm S.E.M are represented in the figure. The global fluorescence intensity analysis of KCC2 has been normalized to the number of cells contained in the ROIs. The $3 \mathrm{D}$ object counter pluggin from Fiji software was used to count the number of cells.

\section{Statistical Analysis}

Data are expressed as mean \pm S.E.M. Statistical analyses were performed using GraphpadPrism (GraphPad software 6.01). For comparison between groups with normal distribution, the two-sample unpaired or paired Student's $t$ test was used for two groups. When data were not normally distributed, the Mann-Whitney rank-sum test (for unpaired data) was performed. For two-factor analysis, $p$ values were determined by Tukey multiple-comparison test following two-way ANOVA analysis.

\section{RESULTS}

\section{Chronic Treatment with Y-27632 after SE Exacerbates Neuronal Cell Death During Epileptogenesis}

The ROCK-signaling pathway is strongly activated in different trauma models including the kainate model of TLE and its acute inhibition has been shown to have a neuroprotective effect (Jeon 
et al., 2013; Rodriguez-Perez et al., 2013). However, from a clinical perspective it is relevant to investigate the influence of ROCK inhibition in the early post-insult time window. Thus, we examined the effect of daily i.p. administration of the selective ROCK inhibitor Y-27632 from day 1 to day 5 post-SE. In order to establish whether, under control condition, the chronic treatment of Y-27632 affects the cell neuronal death in vivo, we first analyzed the number of Fluorojade B-positive cells in the CA3 region of the hippocampus of control vehicle- and control Y-27632-treated rats (Figures 1A1,2). We observed no Fluorojade B-positive cells in the CA3 region of vehicle- and Y-27632-treated control rats. Similar results were found in the hilar and CA1 regions of the hippocampus (data not shown).

Next, we evaluate the effect of chronic Y-27632 treatment on cell death in a rat pilocarpine model (Figure 1B, experimental paradigm). In the Y-27632-treated pilocarpine rats we observed a statistically significant increase in the number of Fluorojade B-positive cells (Figure 1C2) as compared to pilocarpine vehicle-treated rats (Figure $\mathbf{1 C 1}$ ) at $\mathrm{d} 5$ post $\mathrm{SE}$ in the $\mathrm{CA} 3$ region of the hippocampus (Figure 1D; pilocarpine vehicletreated rats $40.43 \pm 2.71$ vs. pilocarpine Y-27632-treated rats: $\left.62.33 \pm 2.12 ;{ }^{* * *} p<0.001\right)$. In contrary to the previously described acute neuroprotective effects of ROCK-inhibition, we found that the drug Y-27632 exacerbated neuronal cell death during early epileptogenesis in a rat pilocarpine model. Although the concentration used of the ROCK inhibitor is similar to previously reported, there is the possibility that the detrimental effect of Y-27632 are derived from concentration dependent nonspecific effects. For this reason we also assessed the effect of $5 \mathrm{mg} / \mathrm{kg}$ i.p. injection of ROCK inhibitor.

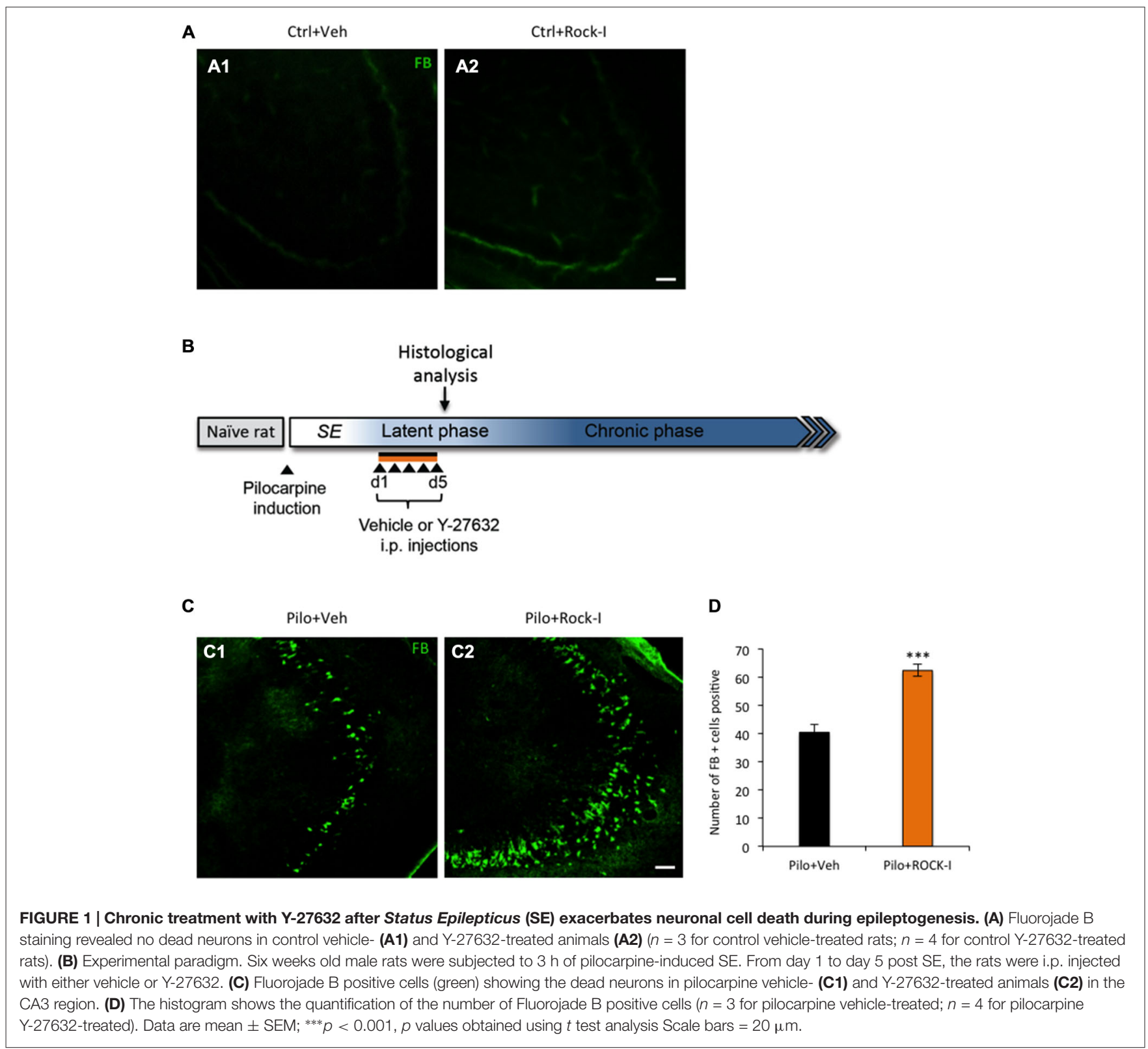


We did not observed any effect on cell death in control treated or pilocarpine treated animal groups (pilocarpine vehicletreated: $39 \pm 2.43$ vs. pilocarpine Y-27632-treated: $45 \pm 2.32$; $p=0.105$, unpaired $t$ test, data are mean \pm SEM; data not shown).

\section{Y-27632 Treatment Increases Early Ectopic Recurrent Mossy Fiber Sprouting}

The ectopic recurrent MF sprouting (rMFS) within the dentate gyrus of the hippocampus is a major feature of TLE in both human patients and animal models (Tauck and Nadler, 1985; Represa et al., 1989; Sutula et al., 1989; Buckmaster et al., 2002; Buckmaster, 2012). This rMFS induces a strong recurrent excitatory circuit within the DG, and is partly responsible for the generation of epileptiform activities in human patients and animal models of TLE (Tauck and Nadler, 1985; Represa et al., 1989; Epsztein et al., 2005; Peret et al., 2014; Shima et al., 2015). Some studies suggest that rMFS is established during the early phase of epileptogenesis (Mathern et al., 1999; Harvey and Sloviter, 2005) and is a consequence of neuronal loss in the CA3 region (Shetty et al., 2005). Immunohistochemical visualization of synaptoporin (SPO) staining in the dorsal hippocampus (Volz et al., 2011; Peret et al., 2014) revealed a marked ectopic band within the molecular layer of DG in pilocarpine vehicle- and Y-27632-treated rats at d5pSE (as shown by the arrowheads in Figures 2B1,3 and Figures 2B2,4; the granular cell layer is labeled in green using the neurotracer marker, Figures 2A3,4-B3,4). As expected, rMFS was absent in control conditions (as shown by the empty arrowheads in Figures 2A1-4; both in control vehicle- and Y-27632-treated rats). The fluorescence intensity of the ectopic band within the molecular layer of DG was higher in pilocarpine Y-27632-treated rats as compared to pilocarpine vehicle-treated rats (Figure 2C; control vehicle-treated rats: $1.00 \pm 0.17$; control Y-27632-treated rats: $1.01 \pm 0.09$; pilocarpine vehicle-treated rats $3.27 \pm 0.12$; pilocarpine Y-27632-treated rats: $3.73 \pm 0.13$; ${ }^{*} p<0.05$ and $* * * p<0.001)$. Thus, these results are in accordance with an increased neuronal death in the CA3 region induced by ROCK inhibition in pilocarpine rats.

\section{Different Glial Response upon Y-27632 Treatment in Control and Post SE Conditions}

The Rho-ROCK pathway seems to play a key role in neuronal survival and astroglial inflammatory responses (Kubo et al., 2008). Reactive gliosis and neuronal death are major events following SE and are thought to contribute to the pathogenesis of TLE (McNamara, 1994; Curia et al., 2008; do Nascimento et al., 2012). Despite the clear involvement of the Rho-ROCK pathway in microglia activation and astrogliosis, the qualitative effect of inhibiting this pathway may vary depending on the experimental model (for review, see Kubo et al., 2008; Fujita and Yamashita, 2014; Hensel et al., 2015). Moreover, few studies have demonstrated the implication of Rho-ROCK signaling pathway in neuronal survival and inflammatory response under epileptic conditions (Inan and Büyükafșar, 2008; Jeon et al., 2013). Thus, we investigated if the inhibitor Y-27632 influenced astrogliosis and if this could explain the increased neuronal cell death described at d5 post SE.

We first studied the effect of Y-27632 treatment on astrogliosis on control rats. Surprisingly, we observed a significant increase in GFAP fluorescence intensity in Y-27632treated control rats (Figure 3A2) as compared to vehicletreated control rats (Figure 3A1; Figure 3B, control vehicletreated rats $1.00 \pm 0.07$ vs. control Y-27632-treated rats: 1.78 $\left.\pm 0.09 ;^{* * *} p<0.001\right)$. The chronic ROCK inhibitor treatment also altered the morphology of GFAP-positive astrocytes (Figures 3A3,4). The astrocytes had a more elongated shape, with long processes (Figure 3A4). In conclusion, our results show that the chronic ROCK inhibitor Y-27632 treatment under control conditions increased the astrocyte-mediated inflammatory response which was interestingly not concomitant to neuronal death.

Next, we evaluate the effect of chronic Y-27632 treatment on astrogliosis in the rat pilocarpine model (see Figure 1B, experimental paradigm). Unlike in control conditions, we showed that reactive astrogliosis was substantially decreased in pilocarpine Y-27632-treated rats at $\mathrm{d} 5$ post SE rats (Figure 3C2) as compared to pilocarpine vehicle-treated rats (Figure 3C1) (Figure 3D; pilocarpine vehicle-treated rats $1.00 \pm 0.02$ vs. pilocarpine Y-27632-treated rats: $0.74 \pm 0.02$; ${ }^{* * *} p<0.001$ ). This was accompanied by morphological changes of GFAPpositive astrocytes after ROCK inhibition, with a retraction of the processes and astrocytes having an amyboïd shape (Figures 3C3,4). Altogether, we showed that chronic ROCK inhibitor Y-27632 treatment reduces astrocyte density during epileptogenesis in the pilocarpine rat model. Thus, these data disclose an intricate relationship between changes in astroglial morphology and SE-induced cell death and indicate that the effect of ROCK inhibition on neuronal cell death may largely not depend on astroglial changes.

\section{Y-27632 Treatment During Epileptogenesis Alters KCC2 Expression}

In addition to the neuronal loss and reactive gliosis, TLE is also characterized by an impaired GABAergic inhibition. KCC2 is one of the chloride co-transporter responsible for establishing the neuronal $\mathrm{Cl}^{-}$gradient that governs GABAergic inhibition. Under epileptic conditions, KCC2 is downregulated which leads to impaired GABAergic inhibition in both human patients and animal models of TLE (Palma et al., 2006; Huberfeld et al., 2007; Pathak et al., 2007; Bragin et al., 2009; Barmashenko et al., 2011). Importantly, recent results directly involve KCC2 in the post-traumatic events leading to neuronal cell lost (Pellegrino et al., 2011; Winkelmann et al., 2015). With this as a background, we assessed the effect of ROCK inhibitor Y-27632 on KCC2 expression under control and epileptic conditions. In the CA3 region of control vehicle- and Y-27632-treated rats, KCC2 immunostaining was strong (Figures 4A1,2); the intensity of staining was not significantly different between the two groups (Figure 4B; control vehicle-treated rats $1.00 \pm 0.07$ vs. control Y-27632-treated rats: $0.86 \pm 0.02 ; p>0.05)$. In control 
A

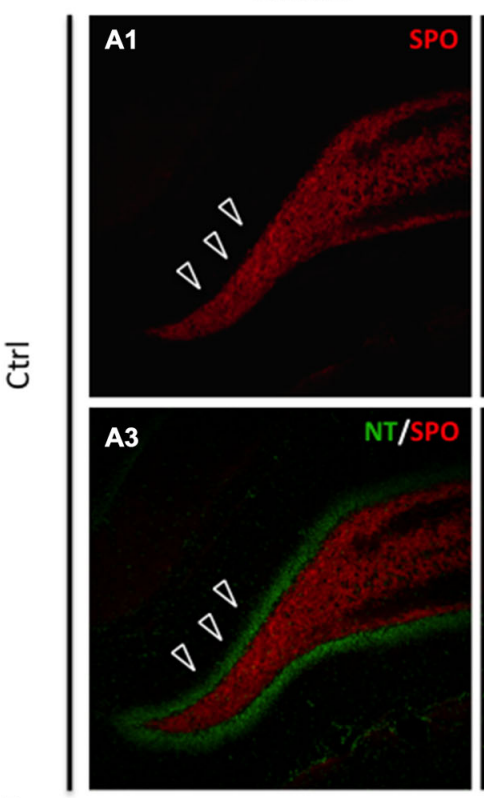

B

B1

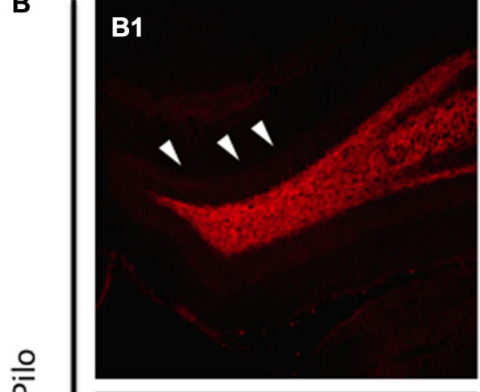

B3

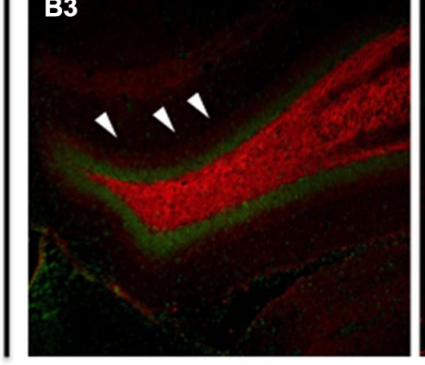

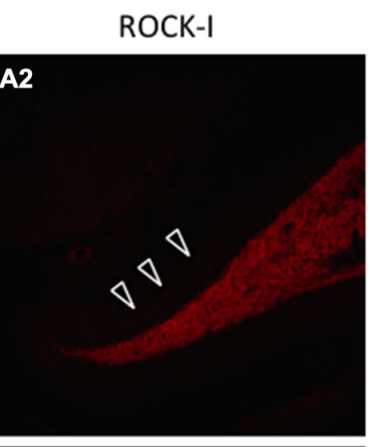

A4

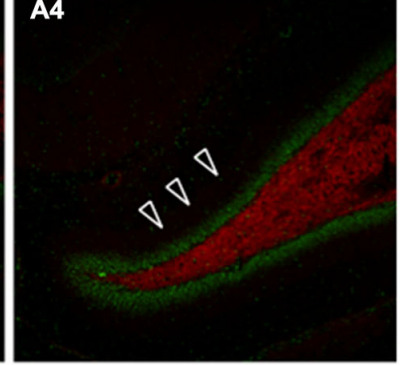

B2

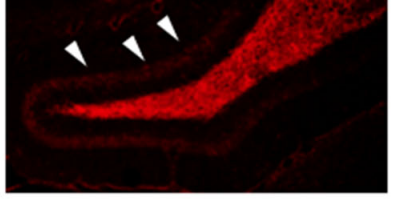

B4

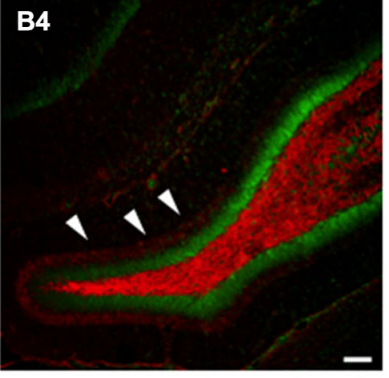

c

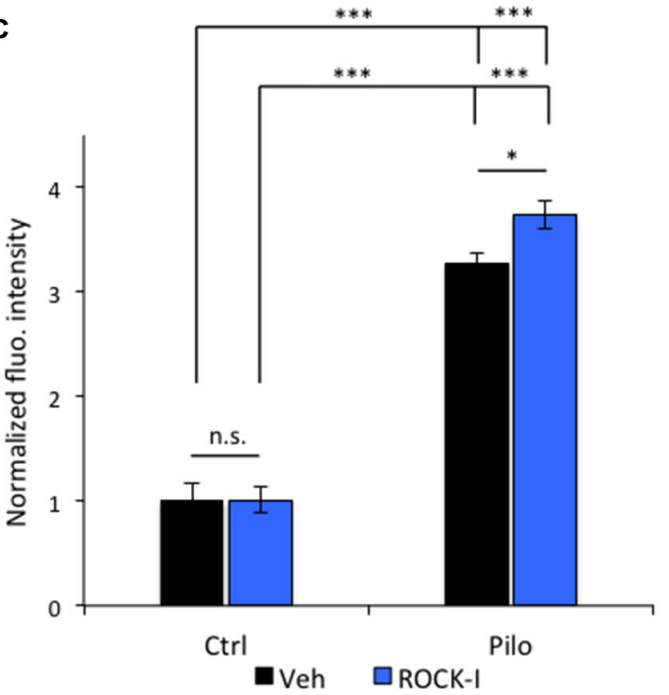

FIGURE 2 | Y-27632 treatment increases early ectopic recurrent mossy fiber sprouting (rMFS) in the dentate gyrus of pilocarpine rats.

Immunohistochemical staining with synaptoporin antibody (SPO, red) labeled the mossy fibers and neurotracer staining (NT, green) labeled cell body of the DG granule cells. (A) Synaptoporin staining revealed no ectopic rMFS band in the molecular layer of the DG in both ventral and dorsal DG in control vehicle- (A1,3; empty arrowheads) and Y-27632-treated rats (A2,4; empty arrowheads). (B) Synaptoporin staining revealed an ectopic rMFS band in the molecular layer of the DG in both ventral and dorsal DG in pilocarpine vehicle- (B1,3; arrowheads) and Y-27632-treated rats (B2,4; arrowheads). (C) The histogram represents the quantification of the fluorescence intensity of synaptoporin in control vehicle- and Y-27632-treated, and pilocarpine vehicle- and Y-27632-treated rats. The data are normalized to control vehicle-treated rats ( $n=3$ for control vehicle-treated rats; $n=4$ for control Y-27632-treated rats; $n=3$ for pilocarpine vehicle-treated; $n=4$ for pilocarpine Y-27632-treated). Data are means \pm SEM; ${ }^{*} p<0.05 ;{ }^{* * *} p<0.001, p$ values were determined by Tukey multiple-comparison test following two-way ANOVA analysis. Scale bar $=20 \mu \mathrm{m}$.

Y-27632-treated rats, similar intensity and pattern of expression was observed (Figures 4A3,4). At higher magnification, we can see that KCC2 immunolabeling is expressed in the perisomatic region of CA3 pyramidal cells (stained using NeuN antibody) in both conditions (Figures 4A1,2 and insert boxes). To confirm these observations, we analyzed the intensity and repartition of KCC2 plotted as a function of pixel distance across the soma. The overall pattern of expression of KCC2 is comparable in control vehicle- and Y-27632-treated rats with a narrow peak at the perisomatic level (Figure 4C, arrowhead); with a significantly 

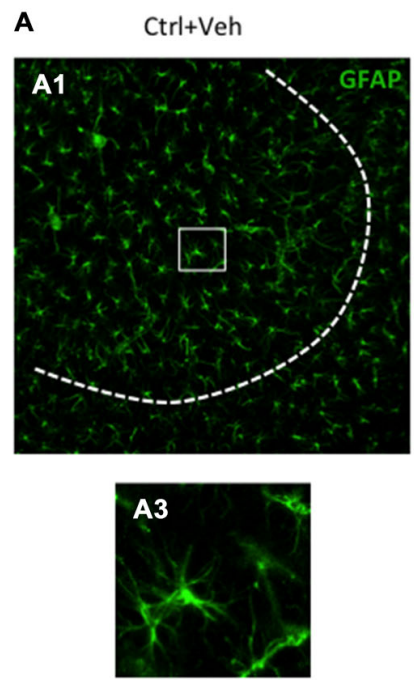

C
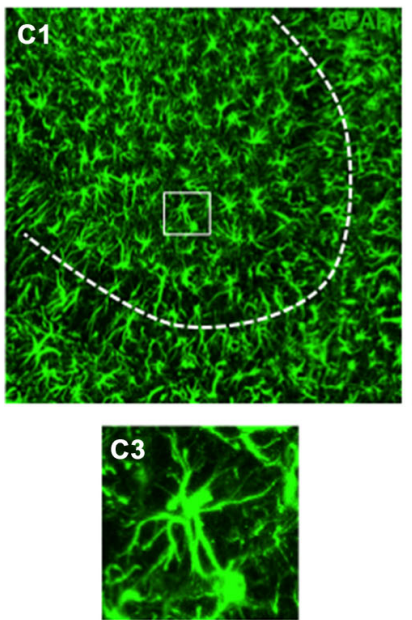

Ctrl+Rock-I
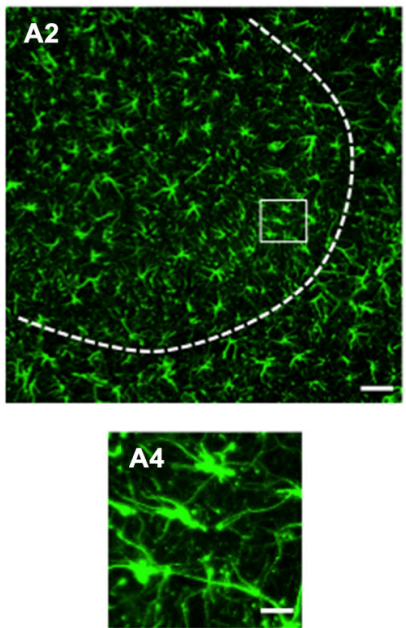

Pilo+Rock-
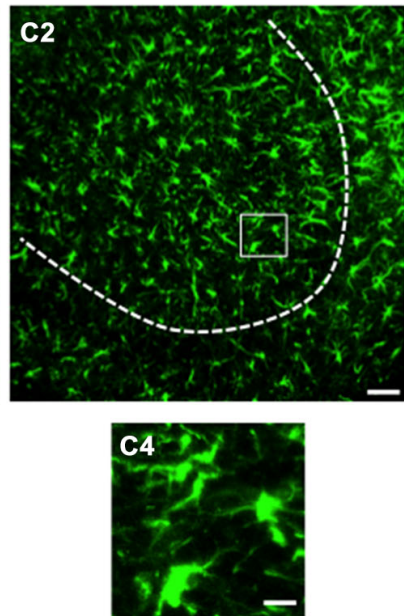

B

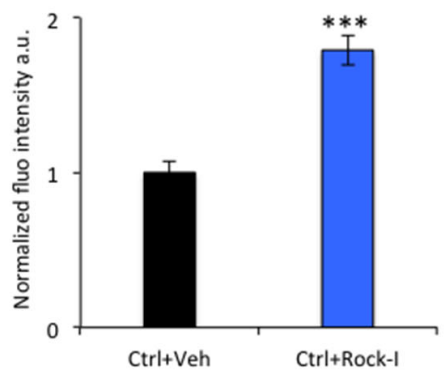

D

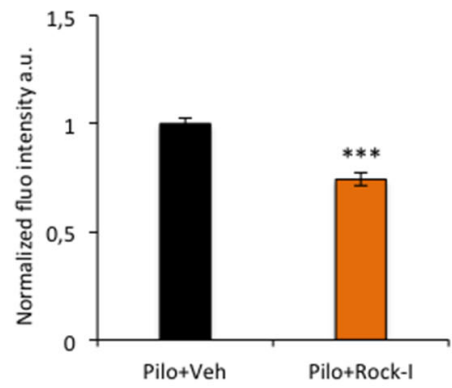

FIGURE 3 | Different glial responses upon Y-27632 treatment in control and post-SE conditions. (A) Representative images of GFAP-immunopositive astrocytes (green) in control vehicle-treated $\mathbf{( A 1 , 3 )}$ and Y27632-treated $\mathbf{( A 2 , 4 )}$ rats. Dotted lines indicate the pyramidal cell layer of the CA3. The white squares in $(\mathbf{A 1}, \mathbf{2})$ show higher magnifications of GFAP labeling $(\mathbf{A} \mathbf{3}, \mathbf{4})$. (B) The histogram represents the quantification of the fluorescence intensity $(n=3$ for control vehicle-treated; $n=4$ for control Y-27632-treated). Data are means \pm SEM; **** $p<0.001, p$ values obtained using Mann-Whitney rank-sum test analysis. (C) Representative images of GFAP-immunopositive astrocytes (green) in the CA3 region in pilocarpine vehicle-treated $\mathbf{( C 1 , 3 )}$ and pilocarpine Y27632-treated (C2,4)

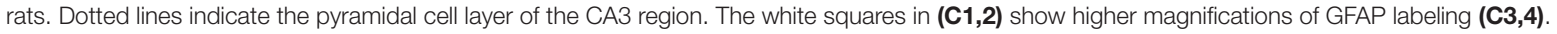

(D) The histogram represents the quantification of the fluorescence intensity ( $n=4$ for pilocarpine vehicle-treated; $n=8$ for pilocarpine Y-27632-treated). Data are means \pm SEM; *** $p<0.001, p$ values obtained using Mann-Whitney rank-sum test analysis. Scale bars: A1, 2; C1, 2 = 20 $\mu$ m. A3, 4; C3, $4=15 \mu m$.

but minor difference in the cytoplasm and in the external part of the cells (Figure 4C, asterisks, $p<0.05$ ). Those results prompt us to conclude that ROCK inhibitor Y-27632 has no overall effect on KCC2 expression pattern under control conditions.

We next investigated the effect of ROCK inhibitor Y-27632 treatment on KCC2 expression in the pilocarpine rats. Interestingly, we observed a lower KCC2 immunoreactvity in the CA3 pyramidal layer as well as in layers containing the dendritic trees (stratum oriens and stratum radiatum) in pilocarpine Y-27632-treated rats (Figures 4D2,4) as compared to pilocarpine vehicle-treated rats (Figures 4D1,3). These observations were confirmed by the analysis of fluorescence intensity showing a significantly decreased intensity in pilocarpine Y-27632-treated rats as compared to pilocarpine vehicle-treated rats (Figure 4E; pilocarpine vehicle-treated rats $1.00 \pm 0.08$ vs. control Y-27632-treated rats: $0.53 \pm 0.04$; $\left.{ }^{*} p<0.05\right)$. The intensity and repartition analysis of KCC2 staining show that KCC2 was very low and diffuse within the neuron cell bodies in both conditions (Figures 4D,F). In pilocarpine Y-27632-treated rats, the cytoplasmic levels of KCC2 immunostaining were significantly decreased as compared to pilocarpine vehicle-treated (Figure $4 \mathrm{~F},{ }^{* * *} p<0.01$ ). Moreover, 
A
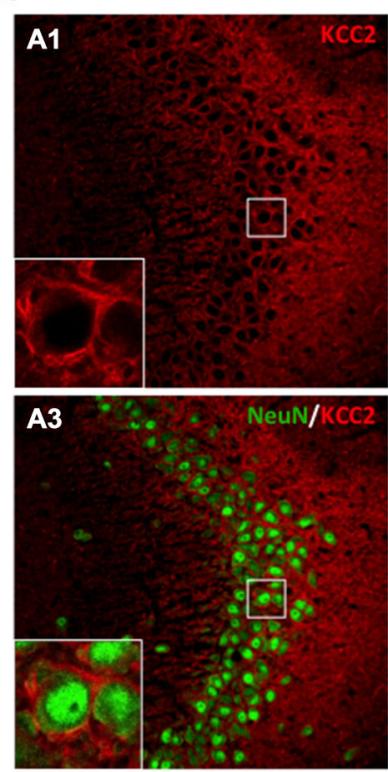

D
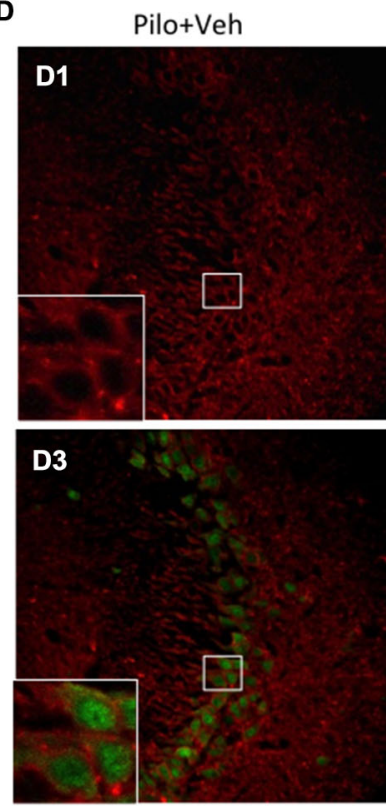

Ctrl+Rock-l
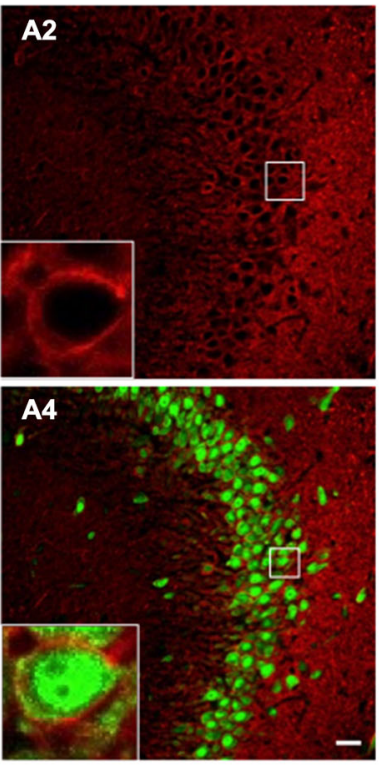

Pilo+ROCK-I
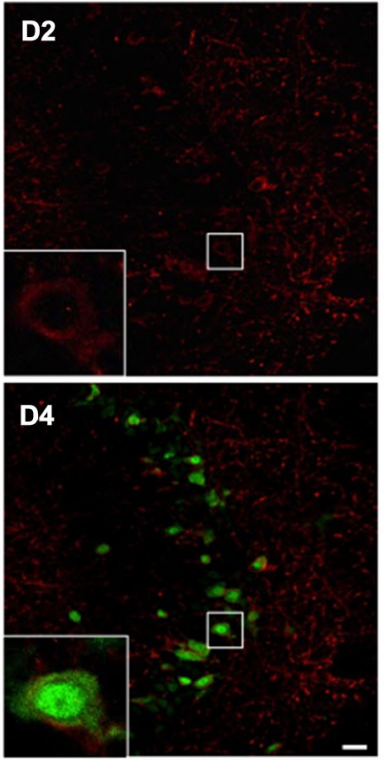

B
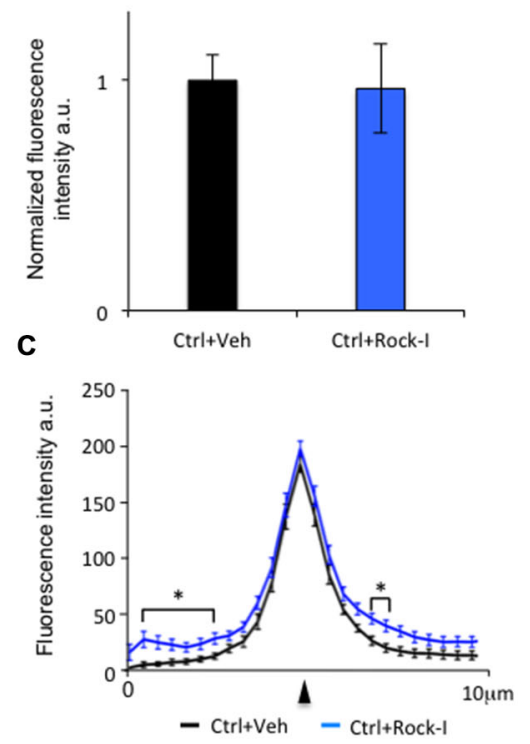

E
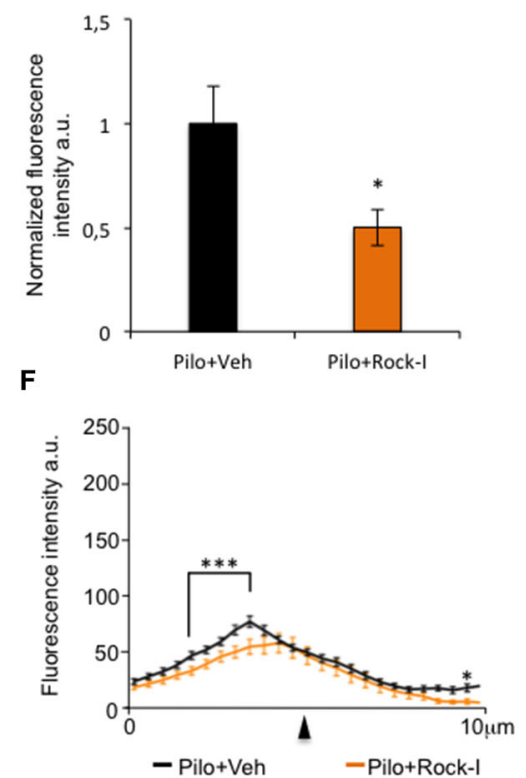

FIGURE 4 | Y-27632 treatment during epileptogenesis alters KCC2 expression in the CA3 region. (A) Immunohistochemical stainings with KCC2 antibody (red) and NeuN (green) in the CA3 region of control vehicle- $\mathbf{( A 1 , 3 )}$ and Y-27632-treated animals $\mathbf{( A 2 , 4 ) . ~ T h e ~ w h i t e ~ s q u a r e s ~ i n ~ ( A 1 - 4 ) ~ s h o w ~ h i g h e r ~ m a g n i f i c a t i o n s ~ o f ~}$ KCC2 labeling. (B) The histogram represents the quantification of the fluorescence of KCC2 labeling in control vehicle- and Y-27632-treated animals. The data are normalized to control. (C) The curves represent the plot profile of $\mathrm{KCC} 2$ staining along $10 \mu \mathrm{m}$ from the nucleus to the external neuropil of the neurons analyzed. The arrowhead indicates the putative membrane location ( $n=3$ for control vehicle-treated; $n=4$ for control Y-27632-treated). (D) Immunohistochemical stainings with KCC2 antibody (red) and NeuN (green) in the CA3 region in pilocarpine vehicle- (D1,3) or with Y-27632-treated animals (D2,4). The white squares in (D1-4) show higher magnifications of KCC2 labeling. (E) The histogram represents the quantification of the fluorescence of KCC2 labeling in pilocarpine vehicle- or with Y-27632-treated animals. The data are normalized to pilocarpine vehicle-treated rats. (F) The curves represent the plot profile of KCC2 staining along $10 \mu \mathrm{m}$ from the nucleus to external neuropil of the neurons analyzed ( $n=4$ for pilocarpine vehicle-treated; $n=8$ for pilocarpine $\mathrm{Y}$-27632-treated). Data are means $\pm \mathrm{SEM}$; ${ }^{p} p<0.05$; ${ }^{* * *} p<0.001, p$ values obtained using $t$ test analysis. Scale bars $=20 \mu \mathrm{m}$.

we also assessed the effect of $5 \mathrm{mg} / \mathrm{kg}$ i.p. injection of ROCK inhibitor and did not observed any effect on KCC2 expression in control treated or pilocarpine treated animal groups (control vehicle-treated: $1.00 \pm 0.09$; control Y-27632-treated: 1.03 $\pm 0.12 ; p=0.65$, unpaired $t$ test; pilocarpine vehicle-treated: $1.00 \pm 0.11$ vs. pilocarpine Y-27632-treated: $0.90 \pm 0.11$; 
$p=0.54$, unpaired $t$ test, data are mean \pm SEM; data not shown).

Altogether, these results show that chronic ROCK inhibitor Y-27632 treatment has a detrimental effect on KCC2 expression during epileptogenesis and not under control conditions. Thus, we found that chronic ROCK inhibition treatment exacerbates the pilocarpine-induced down-regulation of KCC2 and this could play an important role in the mechanism mediating the neuronal loss induced by this inhibitor during epileptogenesis.

\section{DISCUSSION}

The RhoA pathway and its downstream effector ROCK are activated under various pathological conditions including Alzheimer's (Zhou et al., 2003) and Parkinson's diseases (Rodriguez-Perez et al., 2013), spinal cord injury (Fournier et al., 2003), global cerebral ischemia (Castro-Alvarez et al., 2011), traumatic brain injury (Dubreuil et al., 2006) as well as in epilepsy (Dubreuil et al., 2006; Inan and Büyükafșar, 2008; Jeon et al., 2013). Besides, the ROCK signaling pathway is involved in numerous fundamental cellular functions such as cell adhesion, apoptosis, inflammatory responses and neurite outgrowth (see for review, Kubo et al., 2008; Fujita and Yamashita, 2014; Hensel et al., 2015). To this end, several drugs such as Fasudil or Y-27632 have been developed to inhibit ROCK activity in order to treat the diverse pathological conditions where RhoA-ROCK signaling pathway is activated (Kubo et al., 2008). Importantly, ROCK inhibition using Y-27632 has an acute antiepileptic effect in the PTZ model of epilepsy (Inan and Büyükafșar, 2008), as well as a neuroprotective effect in KAinduced SE when applied acutely prior to the SE (Jeon et al., 2013). Thus, although the acute effect of ROCK inhibition is established, it was desirable to evaluate the impact of the use of inhibitors of this pathway in the early post-SE time window.

In the present study, we have evaluated the effect of chronic ROCK inhibitor Y-27632 treatment during the early phase of epileptogenesis in the rat pilocarpine model. Interestingly, our results uncovered a differential effect of ROCK inhibitor treatment between control and epileptic conditions. Unlike the positive acute effect of ROCK inhibition when applied prior to the onset of SE, we found that chronic Y-27632 treatment after SE resulted in a significant increase in cell death in pilocarpine rats which was followed by augmented ectopic rMFS during early epileptogenesis at d5 post SE. These results could no be explained by an increased reactive astrogliosis after ROCK inhibition as the specific compound Y-27632 reduced reactive astrogliosis during epileptogenesis. Interestingly, we found that Y-27632 treatment exacerbates KCC2 downregulation, a protein that has been recently linked with neuronal cell death (Pellegrino et al., 2011; Winkelmann et al., 2015). However, in control rats, this chronic treatment did not affect cell survival, KCC2 expression, or the rMFS, but increased astrocyte density.

One of the hallmarks of TLE is the ectopic rMFS described in the molecular layer of the dentate gyrus within the hippocampus (Tauck and Nadler, 1985; Represa et al., 1989;
Gabriel et al., 2004; de Lanerolle et al., 2012; Peret et al., 2014; Shima et al., 2015). ROCK activity is involved in the axonal outgrowth and its inhibition, using Y-27632, induces axonal regeneration after spinal cord injury (Fournier et al., 2003). This prompts us to evaluate the extent of ectopic rMFS after chronic Y-27632 treatment during epileptogenesis. Here we have shown that Y-27632 treatment increased ectopic rMFS during early epileptogenesis. The cellular and molecular mechanisms underlying this effect remain unclear. The extent of rMFS has been correlated to seizure frequency (Sutula et al., 1989), mossy cell loss (Houser, 1990; Nadler, 2003; although recently challenged by Jinde et al., 2012) and more importantly to CA3 cell loss (Shetty et al., 2005). Thus, in the present study, the effect of ROCK inhibition on ectopic rMFS during epileptogenesis could also partly reflect the increased cell loss in the CA3 in the pilocarpine model.

Although ROCK inhibition is an attractive therapeutic target, the cellular and molecular mechanisms requiring this pathway are far from being fully understood. ROCK activity is known to be involved in neuronal cell death as well as astroglial and microglial neuroinflammatory responses (Kubo et al., 2008). The present findings show that ROCK inhibition using $\mathrm{Y}-27632$ reduced the reactive astrogliosis at $\mathrm{d} 5$ post $\mathrm{SE}$ in the pilocarpine rats. However, Y-27632 treatment under control conditions increased the density and modified the morphology of astrocytes. A closer look at previous work shows, in fact, that both effect have been observed depending on the pathology and model considered. For instance, in hypoxia-reoxygenation injury (Ding et al., 2010) and in neurodegenerative diseases such as Parkinson's disease (Barcia et al., 2012), ROCK inhibition resulted in a reduction of microglia while in a SOD mouse model of amyotrophic lateral sclerosis (ALS) the ROCK inhibitor Fasudil induced an increase in microglia density and a reduction of reactive astrogliosis (Tönges et al., 2014). Conversely, in a spinal cord injury model, the inhibition of ROCK using Y-27632 resulted in an increase of astrogliosis (Chan et al., 2007). Also the results obtained in the present study in sham treated animals are supported by previous studies reporting that, under control conditions, either Fasudil or Y-27632 increased astrocyte density in vivo (Chan et al., 2007); in vitro, they induced an increase of viability and morphological changes of astrocytes (Lau et al., 2011; O'Shea et al., 2015). Thus, the opposite effects of Y-27632 obtained under control and post-SE conditions suggest that the same pathway is recruited for different cellular processes in a context dependent manner.

Reactive gliosis has been proposed to have positive and negative effects after CNS injury (Sofroniew, 2005; Losi et al., 2012; Burda and Sofroniew, 2014; Jones, 2015). The astrogliosis could mediate pro- as well as anti-inflammatory responses and, in turn, have the potential for neural toxicity as well as neuroprotection. Hence, the increased cell death could be a consequence of a reduced density of reactive gliosis that is known to help for the clearance of extracellular space, especially during insults (Bush et al., 1999). Thus, the relationship between plastic changes in astroglia and ROCK inhibition inducing an increase of cell death appears to be highly complex. 
In our search for a mechanism for the increased neuronal death following Y-27632 treatment, we ask if post-SE changes in GABAergic transmission could be involved. An important factor contributing to epileptogenesis is the excessive intracellular accumulation of chloride. This leads to compromised GABAergic inhibition and hyperexcitability in TLE (Palma et al., 2006; Huberfeld et al., 2007; Muñoz et al., 2007; Bragin et al., 2009; Barmashenko et al., 2011). KCC2 is a major neuronal chloride co-transporter which is responsible for establishing the neuronal $\mathrm{Cl}^{-}$gradient that governs GABAergic inhibition (Medina et al., 2014). Some studies have shown that this transporter is downregulated during epileptogenesis in TLE models of epilepsy (Pathak et al., 2007; Bragin et al., 2009; Barmashenko et al., 2011). In our recent publications we have demonstrated that: (i) $\mathrm{GABA}_{\mathrm{A}}-\mathrm{R}$ mediated depolarization triggers RhoA-ROCK activation in an in vitro axotomy model (Shulga et al., 2012) and (ii) an interaction between KCC2 and small Rho GTPases influence actin dynamics and spinogenesis (Llano et al., 2015). In the present study, we show that the treatment with Y-27632 for a few days post SE had no effect under control condition but could delay the post SE KCC2 recovery or exacerbate KCC2 downregulation in pilocarpine rats. Previous reports have shown that excessive glutamate levels can lead to loss of KCC2 expression and function and the abolition of the hyperpolarizing effect of GABAergic transmission (Lee et al., 2011). Importantly, recent results directly linked KCC2 to proapoptotic mechanisms. Pellegrino et al. (2011) have shown that KCC2 loss increases cell vulnerability to toxicity and subsequent cell death. In this study, the authors demonstrated a correlation between the survival rate of neurons after excitotoxic insult in vitro (30 min of $40 \mu \mathrm{M}$ NMDA application in cultured hippocampal neurons) and the recovery of KCC2 expression within the $24 \mathrm{~h}$ following the insult (Pellegrino et al., 2011). Moreover, Winkelmann and collaborators showed an important role of the N-terminal domain of KCC2 in glutamate induced neuronal apoptosis (Winkelmann et al., 2015). Thus, our data on KCC2 expression in pilocarpine rats suggest that the ROCK signaling pathway could be involved in the recovery of KCC2 after an excitotoxic insult, such as an SE episode, and that this delay subsequently induce neuronal loss. This

\section{REFERENCES}

Artinian, J., Peret, A., Marti, G., Epsztein, J., and Crépel, V. (2011). Synaptic kainate receptors in interplay with $\mathrm{INaP}$ shift the sparse firing of dentate granule cells to a sustained rhythmic mode in temporal lobe epilepsy. J. Neurosci. 31, 10811-10818. doi: 10.1523/jneurosci.038811.2011

Barcia, C., Ros, C. M., Annese, V., Carrillo-de Sauvage, M. A., RosBernal, F., Gómez, A., et al. (2012). ROCK/Cdc42-mediated microglial motility and gliapse formation lead to phagocytosis of degenerating dopaminergic neurons in vivo. Sci. Rep. 2:809. doi: 10.1038/srep 00809

Barmashenko, G., Hefft, S., Aertsen, A., Kirschstein, T., and Köhling, R. (2011). Positive shifts of the GABAA receptor reversal potential due to altered chloride homeostasis is widespread after status epilepticus. Epilepsia 52, 1570-1578. doi: $10.1111 / j .1528-1167.2011 .03247 . x$ is interesting in view that studies have shown a recovery of KCC2 expression that could be cell type specific (e.g., Huberfeld et al., 2007). Thus, it will be important to investigate whether differential ROCK signaling could be involved in this phenomenon.

The underlying mechanisms of KCC2 downregulation seem to involve the phosphorylation state of KCC2 (Lee et al., 2011; for review, see Medina et al., 2014). Interestingly, in a recent report, the activation of RhoA-ROCK-PTEN pathway was shown to decrease the phosphorylation levels of $\mathrm{GABA}_{\mathrm{A}}$-Rs and to trigger endocytosis and degradation of internalized receptors (Riffault et al., 2014). A similar mechanism could affect the expression of KCC2 in the presence of the inhibitor Y-27632.

In conclusion, our findings evaluate for the first time the chronic use of the ROCK inhibitor Y-27632 as a post SE prophylactic drug during epileptogenesis in the pilocarpine model. Our study suggests that this treatment has an overall detrimental effect on major morphological features and neuronal survival after SE. While the data show an intricate involvement of astrogliosis, they suggest that post SE activation of the ROCK pathway acts to maintain KCC2 expression. This may, in turn, constitute part of a pro-survival mechanism during the epileptogenic window following SE. Further investigations are necessary to decipher, in more detail, the mechanisms of ROCK activation in astrogliosis, rMFS and KCC2 expression in the events leading to the development of chronic epilepsy.

\section{ACKNOWLEDGMENTS}

This work was supported by the Institut National de la Santé et de la Recherche Médicale (INSERM), Aix-Marseille Université (AMU), University of Helsinki, the Agence Nationale de la Recherche (ANR) (TRAUMEP ANR 13-BSV4-0012-02 to CR and Valerie Crepel), Academy of Finland (SA 259799 to CR), the Ministère de l'Enseignement Supérieur et de la Recherche (MESR to NK), and the Ligue Française Contre l'Epilepsie (LFCE to NK). This work was performed with the help of the imaging platform InMagic headed by Dr. François Michel and the animal house facility headed by Séverine Corby-Pellegrino at INMED. We also would like to thank F. Haigler for English comments on the manuscript.

Bernhardt, B. C., Hong, S., Bernasconi, A., and Bernasconi, N. (2013) Imaging structural and functional brain networks in temporal lobe epilepsy. Front. Hum. Neurosci. 7:624. doi: 10.3389/fnhum.2013. 00624

Bonislawski, D. P., Schwarzbach, E. P., and Cohen, A. S. (2007). Brain injury impairs dentate gyrus inhibitory efficacy. Neurobiol. Dis. 25, 163-169. doi: 10. 1016/j.nbd.2006.09.002

Boomkamp, S. D., Riehle, M. O., Wood, J., Olson, M. F., and Barnett, S. C. (2012). The development of a rat in vitro model of spinal cord injury demonstrating the additive effects of Rho and ROCK inhibitors on neurite outgrowth and myelination. Glia 60, 441-456. doi: 10.1002/glia. 22278

Bragin, D. E., Sanderson, J. L., Peterson, S., Connor, J. A., and Müller, W. S. (2009). Development of epileptiform excitability in the deep entorhinal cortex after status epilepticus. Eur. J. Neurosci. 30, 611-624. doi: 10.1111/j.1460-9568.2009. 06863.x 
Buckmaster, P. S. (2012). "Mossy fiber sprouting in the dentate gyrus," in Jasper's Basic Mechanisms of the Epilepsies [Internet]. 4th Edn, eds J. L. Noebels, M. Avoli, M. A. Rogawski, R. W. Olsen, and A. V. Delgado-Escueta (Bethesda, MD: National Center for Biotechnology Information), 9-17.

Buckmaster, P. S., Zhang, G. F., and Yamawaki, R. (2002). Axon sprouting in a model of temporal lobe epilepsy creates a predominantly excitatory feedback circuit. J. Neurosci. 22, 6650-6658.

Burda, J. E., and Sofroniew, M. V. (2014). Reactive gliosis and the multicellular response to CNS damage and disease. Neuron 81, 229-248. doi: 10.1016/j. neuron.2013.12.034

Bush, T. G., Puvanachandra, N., Horner, C. H., Polito, A., Ostenfeld, T., Svendsen, C. N., et al. (1999). Leukocyte infiltration, neuronal degeneration and neurite outgrowth after ablation of scar-forming, reactive astrocytes in adult transgenic mice. Neuron 23, 297-308. doi: 10.1016/s0896-6273(00)80781-3

Castro-Alvarez, J. F., Gutierrez-Vargas, J., Darnaudéry, M., and CardonaGómez, G. P. (2011). ROCK inhibition prevents tau hyperphosphorylation and p25/CDK5 increase after global cerebral ischemia. Behav. Neurosci. 125, 465-472. doi: 10.1037/a0023167

Cavalheiro, E. A., Leite, J. P., Bortolotto, Z. A., Turski, W. A., Ikonomidou, C., and Turski, L. (1991). Long-term effects of pilocarpine in rats: structural damage of the brain triggers kindling and spontaneous recurrent seizures. Epilepsia 32, 778-782. doi: 10.1111/j.1528-1157.1991.tb05533.x

Chan, C. C. M., Wong, A. K., Liu, J., Steeves, J. D., and Tetzlaff, W. (2007). ROCK inhibition with Y27632 activates astrocytes and increases their expression of neurite growth-inhibitory chondroitin sulfate proteoglycans. Glia 55, 369-384. doi: 10.1002/glia.20466

Cossart, R., Bernard, C., and Ben-Ari, Y. (2005). Multiple facets of GABAergic neurons and synapses: multiple fates of GABA signalling in epilepsies. TINS 28, 108-115. doi: 10.1016/j.tins.2004.11.011

Curia, G., Longo, D., Biagini, G., Jones, R. S. G., and Avoli, M. (2008). The pilocarpine model of temporal lobe epilepsy. J. Neurosci. Methods 172, 143-157. doi: 10.1016/j.jneumeth.2008.04.019

D’Amour, J., Magagna-Poveda, A., Moretto, J., Friedman, D., LaFrancois, J. J., Pearce, P., et al. (2015). Interictal spike frequency varies with ovarian cycle stage in a rat model of epilepsy. Exp. Neurol. 269, 102-119. doi: 10.1016/j.expneurol. 2015.04.003

Davies, S. P., Reddy, H., Caivano, M., and Cohen, P. (2000). Specificity and mechanism of action of some commonly used protein kinase inhibitors. Biochem. J. 351, 95-105. doi: 10.1042/bj3510095

de Lanerolle, N. C., Lee, T.-S., and Spencer, D. D. (2012). "Histopathology of human epilepsy," in Jasper's Basic Mechanisms of the Epilepsies [Internet]. 4th Edn, eds J. Noebels, M. Avoli, M. Rogawski, R. Olsen, and A. DelgadoEscueta (Bethesda, MD: National Center for Biotechnology Information), 387.

Ding, J., Li, Q.-Y., Wang, X., Sun, C.-H., Lu, C.-Z., and Xiao, B.-G. (2010). Fasudil protects hippocampal neurons against hypoxia-reoxygenation injury by suppressing microglial inflammatory responses in mice. J. Neurochem. 114, 1619-1629. doi: 10.1111/j.1471-4159.2010.06876.x

do Nascimento, A. L., Dos Santos, N. F., Campos Pelágio, F., Aparecida Teixeira, S., de Moraes Ferrari, E. A., and Langone, F. (2012). Neuronal degeneration and gliosis time-course in the mouse hippocampal formation after pilocarpineinduced status epilepticus. Brain Res. 1470, 98-110. doi: 10.1016/j.brainres. 2012.08.009

Dubreuil, C. I., Marklund, N., Deschamps, K., McIntosh, T. K., and McKerracher, L. (2006). Activation of Rho after traumatic brain injury and seizure in rats. Exp. Neurol. 198, 361-369. doi: 10.1016/j.expneurol.2005.12.002

Dudek, F. E., and Sutula, T. P. (2007). Epileptogenesis in the dentate gyrus: a critical perspective. Prog. Brain Res. 163, 755-773. doi: 10.1016/s00796123(07)63041-6

Edwards, H. E., Burnham, W. M., and MacLusky, N. J. (1999). Testosterone and its metabolites affect afterdischarge thresholds and the development of amygdala kindled seizures. Brain Res. 838, 151-157. doi: 10.1016/s0006-8993(99)01620-0

Engel, J., McDermott, M. P., Wiebe, S., Langfitt, J. T., Stern, J. M., Dewar, S., et al. (2012). Early surgical therapy for drug-resistant temporal lobe epilepsy: a randomized trial. JAMA 307, 922-930. doi: 10.1001/jama. 2012.220

Epsztein, J., Represa, A., Jorquera, I., Ben-Ari, Y., and Crépel, V. (2005). Recurrent mossy fibers establish aberrant kainate receptor-operated synapses on granule cells from epileptic rats. J. Neurosci. 25, 8229-8239. doi: 10.1523/jneurosci. 1469-05.2005
Esclapez, M., Hirsch, J. C., Ben-Ari, Y., and Bernard, C. (1999). Newly formed excitatory pathways provide a substrate for hyperexcitability in experimental temporal lobe epilepsy. J. Comp. Neurol. 408, 449-460. doi: 10.1002/(sici)10969861(19990614)408:4<449::aid-cne1>3.0.co;2-r

Fournier, A. E., Takizawa, B. T., and Strittmatter, S. M. (2003). Rho kinase inhibition enhances axonal regeneration in the injured CNS. J. Neurosci. 23, 1416-1423.

Fujita, Y., and Yamashita, T. (2014). Axon growth inhibition by RhoA/ROCK in the central nervous system. Front. Neurosci. 8:338. doi: 10.3389/fnins.2014. 00338

Gabriel, S., Njunting, M., Pomper, J. K., Merschhemke, M., Sanabria, E. R. G., Eilers, A., et al. (2004). Stimulus and potassium-induced epileptiform activity in the human dentate gyrus from patients with and without hippocampal sclerosis. J. Neurosci. 24, 10416-10430. doi: 10.1523/jneurosci.2074-04.2004

Galanopoulou, A. S. (2008). Sexually dimorphic expression of KCC2 and GABA function. Epilepsy Res. 80, 99-113. doi: 10.1016/j.eplepsyres.2008.04.013

Galanopoulou, A. S., Alm, E. M., and Velišková, J. (2003). Estradiol reduces seizure-induced hippocampal injury in ovariectomized female but not in male rats. Neurosci. Lett. 342, 201-205. doi: 10.1016/s0304-3940(03)00282-9

Galanopoulou, A. S., and Moshé, S. L. (2003). Role of sex hormones in the sexually dimorphic expression of KCC2 in rat substantia nigra. Exp. Neurol. 184, 1003-1009. doi: 10.1016/s0014-4886(03)00387-x

Giorgi, F. S., Galanopoulou, A. S., and Moshé, S. L. (2014). Sex dimorphism in seizure-controlling networks. Neurobiol. Dis. 72, 144-152. doi: 10.1016/j.nbd. 2014.05.010

Gisselsson, L., Toresson, H., Ruscher, K., and Wieloch, T. (2010). Rho kinase inhibition protects $\mathrm{CA} 1$ cells in organotypic hippocampal slices during in vitro ischemia. Brain Res. 1316, 92-100. doi: 10.1016/j.brainres.2009.11.087

Hadera, M. G., Eloqayli, H., Jaradat, S., Nehlig, A., and Sonnewald, U. (2015). Astrocyte-neuronal interactions in epileptogenesis. J. Neurosci. Res. 93, 1157-1164. doi: $10.1002 /$ jnr.23584

Harvey, B. D., and Sloviter, R. S. (2005). Hippocampal granule cell activity and c-Fos expression during spontaneous seizures in awake, chronically epileptic, pilocarpine-treated rats: implications for hippocampal epileptogenesis. J. Comp. Neurol. 488, 442-463. doi: 10.1002/cne.20594

Hensel, N., Rademacher, S., and Claus, P. (2015). Chatting with the neighbors: crosstalk between Rho-kinase (ROCK) and other signaling pathways for treatment of neurological disorders. Front. Neurosci. 9:198. doi: 10.3389/fnins. 2015.00198

Houser, C. R. (1990). Granule cell dispersion in the dentate gyrus of humans with temporal lobe epilepsy. Brain Res. 535, 195-204. doi: 10.1016/00068993(90)91601-c

Huberfeld, G., Wittner, L., Clemenceau, S., Baulac, M., Kaila, K., Miles, R., et al. (2007). Perturbed chloride homeostasis and GABAergic signaling in human temporal lobe epilepsy. J. Neurosci. 27, 9866-9873. doi: 10.1523/jneurosci.276107.2007

İnan, S. Y., and Büyükafșar, K. (2008). Antiepileptic effects of two Rho-kinase inhibitors, Y-27632 and fasudil, in mice. Br. J. Pharmacol. 155, 44-51. doi: 10 1038/bjp.2008.225

Jaenisch, N., Witte, O. W., and Frahm, C. (2010). Downregulation of potassium chloride cotransporter KCC2 after transient focal cerebral ischemia. Stroke 41, e151-e159. doi: 10.1161/strokeaha.109.570424

Jefferys, J. G. R. (2010). Advances in understanding basic mechanisms of epilepsy and seizures. Seizure 19, 638-646. doi: 10.1016/j.seizure.2010.10.026

Jeon, B. T., Jeong, E. A., Park, S.-Y., Son, H., Shin, H. J., Lee, D. H., et al. (2013). The Rho-Kinase (ROCK) inhibitor Y-27632 protects against excitotoxicityinduced neuronal death in vivo and in vitro. Neurotox. Res. 23, 238-248. doi: 10 1007/s12640-012-9339-2

Jinde, S., Zsiros, V., Jiang, Z., Nakao, K., Pickel, J., Kohno, K., et al. (2012). Hilar mossy cell degeneration causes transient dentate granule cell hyperexcitability and impaired pattern separation. Neuron 76, 1189-1200. doi: 10.1016/j.neuron. 2012.10.036

Jones, O. D. (2015). Astrocyte-mediated metaplasticity in the hippocampus: help or hindrance? Curr. Protein Pept. Sci. 1-12. doi: 10.1016/j.neuroscience.2015. 08.035 [Epub ahead of print].

Joshi, A. R., Bobylev, I., Zhang, G., Sheikh, K. A., and Lehmann, H. C. (2015). Inhibition of Rho-kinase differentially affects axon regeneration of peripheral motor and sensory nerves. Exp. Neurol. 263, 28-38. doi: 10.1016/j.expneurol. 2014.09.012 
Kahle, K. T., Merner, N. D., Friedel, P., Silayeva, L., Liang, B., Khanna, A., et al. (2014). Genetically encoded impairment of neuronal KCC2 cotransporter function in human idiopathic generalized epilepsy. EMBO Rep. 15, 766-774. doi: $10.15252 /$ embr. 201438840

Kubo, T., Yamaguchi, A., and Iwata, N. (2008). The therapeutic effects of RhoROCK inhibitors on CNS disorders. Ther. Clin. Risk Manag. 4, 605-615. doi: 10. 2147/TCRM.S2907

Lau, C. L., O'Shea, R. D., Broberg, B. V., Bischof, L., and Beart, P. M. (2011). The Rho kinase inhibitor fasudil up-regulates astrocytic glutamate transport subsequent to actin remodelling in murine cultured astrocytes. $\mathrm{Br}$. J. Pharmacol. 163, 533-545. doi: 10.1111/j.1476-5381.2011.01259.x

Lee, H. H. C., Deeb, T. Z., Walker, J. A., Davies, P. A., and Moss, S. J. (2011). NMDA receptor activity downregulates KCC2 resulting in depolarizing GABAA receptor-mediated currents. Nat. Neurosci. 14, 736-743. doi: 10. 1038/nn.2806

Leonardi, M., and Ustun, T. B. (2002). The global burden of epilepsy. Epilepsia 43(Suppl. 6), 21-25. doi: 10.1046/j.1528-1157.43.s.6.11.x

Llano, O., Smirnov, S., Soni, S., Golubtsov, A., Guillemin, I., Hotulainen, P., et al. (2015). KCC2 regulates actin dynamics in dendritic spines via interaction with $\beta$-PIX. J. Cell Biol. 209, 671-686. doi: 10.1083/jcb.201411008

Losi, G., Cammarota, M. G., and Carmignoto, G. (2012). The role of astroglia in the epileptic brain. Front. Pharmacol. 3:132. doi: 10.3389/fphar.2012.00132

Ludwig, A., Li, H., Saarma, M., Kaila, K., and Rivera, C. (2003). Developmental up-regulation of KCC2 in the absence of GABAergic and glutamatergic transmission. Eur. J. Neurosci. 18, 3199-3206. doi: 10.1111/j.1460-9568.2003. 03069.x

Maguire, J., and Mody, I. (2007). Neurosteroid synthesis-mediated regulation of GABA(A) receptors: relevance to the ovarian cycle and stress. J. Neurosci. 27, 2155-2162. doi: 10.1523/jneurosci.4945-06.2007

Maguire, J. L., Stell, B. M., Rafizadeh, M., and Mody, I. (2005). Ovarian cycle-linked changes in GABAA receptors mediating tonic inhibition alter seizure susceptibility and anxiety. Nat. Neurosci. 8, 797-804. doi: 10. 1038/nn1469

Mathern, G. W., Mendoza, D., Lozada, A., Pretorius, J. K., Dehnes, Y., Danbolt, N. C., et al. (1999). Hippocampal GABA and glutamate transporter immunoreactivity in patients with temporal lobe epilepsy. Neurology 52, 453-472. doi: 10.1212/wnl.52.3.453

McNamara, J. O. (1994). Cellular and molecular basis of epilepsy. J. Neurosci. 14, 3413-3425.

Medina, I., Friedel, P., Rivera, C., Kahle, K. T., Kourdougli, N., Uvarov, P., et al. (2014). Current view on the functional regulation of the neuronal $\mathrm{K}(+)-\mathrm{Cl}(-)$ cotransporter KCC2. Front. Cell. Neurosci. 8:27. doi: 10.3389/fncel.2014.00027

Mejías-Aponte, C. A., Jiménez-Rivera, C. A., and Segarra, A. C. (2002). Sex differences in models of temporal lobe epilepsy: role of testosterone. Brain Res. 944, 210-218. doi: 10.1016/s0006-8993(02)02691-4

Morimoto, K., Fahnestock, M., and Racine, R. J. (2004). Kindling and status epilepticus models of epilepsy: rewiring the brain. Prog. Neurobiol. 73, 1-60. doi: 10.1016/j.pneurobio.2004.03.009

Muñoz, A., Méndez, P., DeFelipe, J., and Alvarez-Leefmans, F. J. (2007). Cation-chloride cotransporters and GABA-ergic innervation in the human epileptic hippocampus. Epilepsia 48, 663-673. doi: 10.1111/j.1528-1167.2007. 00986.x

Nadler, J. V. (2003). The recurrent mossy fiber pathway of the epileptic brain. Neurochem. Res. 28, 1649-1658. doi: 10.1023/A:1026004904199

Nakamura, N. H., Rosell, D. R., Akama, K. T., and McEwen, B. S. (2004). Estrogen and ovariectomy regulate mRNA and protein of glutamic acid decarboxylases and cation-chloride cotransporters in the adult rat hippocampus. Neuroendocrinology 80, 308-323. doi: 10.1159/000083657

Oliveira, C. V., de, Grigoletto, J., Funck, V. R., Ribeiro, L. R., Royes, L. F., Fighera, M. R., et al. (2015). Evaluation of potential gender-related differences in behavioral and cognitive alterations following pilocarpine-induced status epilepticus in C57BL/6 mice. Physiol. Behav. 143, 142-150. doi: 10.1016/j. physbeh.2014.02.058

O'Shea, R. D., Lau, C. L., Zulaziz, N., Maclean, F. L., Nisbet, D. R., Horne, M. K., et al. (2015). Transcriptomic analysis and 3D bioengineering of astrocytes indicate ROCK inhibition produces cytotrophic astrogliosis. Front. Neurosci. 9:50. doi: 10.3389/fnins.2015.00050

Palma, E., Amici, M., Sobrero, F., Spinelli, G., Di Angelantonio, S., Ragozzino, D., et al. (2006). Anomalous levels of $\mathrm{Cl}^{-}$transporters in the hippocampal subiculum from temporal lobe epilepsy patients make GABA excitatory. Proc. Natl. Acad. Sci. U S A 103, 8465-8468. doi: 10.1073/pnas.0602979103

Pathak, H. R., Weissinger, F., Terunuma, M., Carlson, G. C., Hsu, F.-C., Moss, S. J., et al. (2007). Disrupted dentate granule cell chloride regulation enhances synaptic excitability during development of temporal lobe epilepsy. J. Neurosci. 27, 14012-14022. doi: 10.1523/jneurosci.4390-07.2007

Paz, J. T., and Huguenard, J. R. (2015). Microcircuits and their interactions in epilepsy: is the focus out of focus? Nat. Neurosci. 18, 351-359. doi: 10.1038/nn 3950

Pellegrino, C., Gubkina, O., Schaefer, M., Becq, H., Ludwig, A., Mukhtarov, M., et al. (2011). Knocking down of the KCC2 in rat hippocampal neurons increases intracellular chloride concentration and compromises neuronal survival. J. Physiol. 589, 2475-2496. doi: 10.1113/jphysiol.2010.203703

Peret, A., Christie, L. A., Ouedraogo, D. W., Gorlewicz, A., Epsztein, J., Mulle, C., et al. (2014). Contribution of aberrant GluK2-containing kainate receptors to chronic seizures in temporal lobe epilepsy. Cell Rep. 8, 347-354. doi: 10.1016/j. celrep.2014.06.032

Perrot-Sinal, T. S., Sinal, C. J., Reader, J. C., Speert, D. B., and McCarthy, M. M. (2007). Sex differences in the chloride cotransporters, NKCC1 and KCC2, in the developing hypothalamus. J. Neuroendocrinol. 19, 302-308. doi: 10.1111/j. 1365-2826.2007.01530.x

Persinger, M. A., Makarec, K., and Bradley, J.-C. (1988). Characteristics of limbic seizures evoked by peripheral injections of lithium and pilocarpine. Physiol. Behav. 44, 27-37. doi: 10.1016/0031-9384(88)90342-3

Puskarjov, M., Seja, P., Heron, S. E., Williams, T. C., Ahmad, F., Iona, X., et al. (2014). A variant of KCC2 from patients with febrile seizures impairs neuronal $\mathrm{Cl}^{-}$extrusion and dendritic spine formation. EMBO Rep. 15, 723-729. doi: 10. 1002/embr.201438749

Racine, R. J. (1972). Modification of seizure activity by electrical stimulation: II. Motor seizure. Electroencephalogr. Clin. Neurophysiol. 32, 281-294. doi: 10. 1016/0013-4694(72)90177-0

Represa, A., Le Gall La Salle, G., and Ben-Ari, Y. (1989). Hippocampal plasticity in the kindling model of epilepsy in rats. Neurosci. Lett. 99, 345-350. doi: 10. 1016/0304-3940(89)90471-0

Riffault, B., Medina, I., Dumon, C., Thalman, C., Ferrand, N., Friedel, P., et al. (2014). Pro-brain-derived neurotrophic factor inhibits GABAergic neurotransmission by activating endocytosis and repression of GABAA receptors. J. Neurosci. 34, 13516-13534. doi: 10.1523/jneurosci.2069-14.2014

Rodriguez-Perez, A. I., Dominguez-Meijide, A., Lanciego, J. L., Guerra, M. J., and Labandeira-Garcia, J. L. (2013). Inhibition of Rho kinase mediates the neuroprotective effects of estrogen in the MPTP model of Parkinson's disease. Neurobiol. Dis. 58, 209-219. doi: 10.1016/j.nbd.2013.06.004

Rossi, A. R., Angelo, M. F., Villarreal, A., Lukin, J., and Ramos, A. J. (2013). Gabapentin Administration reduces reactive gliosis and neurodegeneration after pilocarpine-induced status epilepticus. PLoS One 8:e78516. doi: 10. 1371/journal.pone.0078516

Scharfman, H. E., Goodman, J. H., Rigoulot, M. A., Berger, R. E., Walling, S. G., Mercurio, T. C., et al. (2005). Seizure susceptibility in intact and ovariectomized female rats treated with the convulsant pilocarpine. Exp. Neurol. 196, 73-86. doi: 10.1016/j.expneurol.2005.07.007

Scharfman, H. E., and MacLusky, N. J. (2006). The influence of gonadal hormones on neuronal excitability, seizures and epilepsy in the female. Epilepsia 47, 1423-1440. doi: 10.1111/j.1528-1167.2006.00672.x

Scharfman, H. E., and MacLusky, N. J. (2014). Sex differences in the neurobiology of epilepsy: a preclinical perspective. Neurobiol. Dis. 72, 180-192. doi: 10.1016/j. nbd.2014.07.004

Schmued, L. C., and Hopkins, K. J. (2000). Fluoro-Jade B: a high affinity fluorescent marker for the localization of neuronal degeneration. Brain Res. 874, 123-130. doi: 10.1016/s0006-8993(00)02513-0

Shetty, A. K., Zaman, V., and Hattiangady, B. (2005). Repair of the injured adult hippocampus through graft-mediated modulation of the plasticity of the dentate gyrus in a rat model of temporal lobe epilepsy. J. Neurosci. 25, 8391-8401. doi: 10.1523/jneurosci.1538-05.2005

Shima, A., Nitta, N., Suzuki, F., Laharie, A.-M., Nozaki, K., and Depaulis, A. (2015). Activation of mTOR signaling pathway is secondary to neuronal excitability in a mouse model of mesio-temporal lobe epilepsy. Eur. J. Neurosci. 41, 974-986. doi: 10.1111/ejn.12835

Shulga, A., Magalhães, A. C., Autio, H., Plantman, S., di Lieto, A., Nykjaer, A., et al. (2012). The loop diuretic bumetanide blocks posttraumatic p75NTR 
upregulation and rescues injured neurons. J. Neurosci. 32, 1757-1770. doi: 10. 1523/jneurosci.3282-11.2012

Shulga, A., Thomas-Crusells, J., Sigl, T., Blaesse, A., Mestres, P., Meyer, M., et al. (2008). Posttraumatic GABAA-Mediated [Ca2+]i increase is essential for the induction of brain-derived neurotrophic factor-dependent survival of mature central neurons. J. Neurosci. 28, 6996-7005. doi: 10.1523/jneurosci.5268-07. 2008

Sloviter, R. S. (1987). Decreased hippocampal inhibition and a selective loss of interneurons in experimental epilepsy. Science 235, 73-76. doi: 10.1126/science. 2879352

Sloviter, R. S. (2008). Hippocampal epileptogenesis in animal models of mesial temporal lobe epilepsy with hippocampal sclerosis: the importance of the "latent period" and other concepts. Epilepsia 49, 85-92. doi: 10.1111/j.15281167.2008.01931.x

Smith, S., O'Keane, V., and Murray, R. (2002). Sexual dysfunction in patients taking conventional antipsychotic medication. Br. J. Psychiatry 181, 49-55. doi: 10.1192/bjp.181.1.49

Smith, P. E., Saunders, J., Dawson, A., and Kerr, M. P. (1999). Intractable seizures in pregnancy. Lancet 354:1522. doi: 10.1016/s0140-6736(99)09164-3

Sofroniew, M. V. (2005). Reactive astrocytes in neural repair and protection. Neuroscientist 11, 400-407. doi: 10.1177/1073858405278321

Stell, B. M., Brickley, S. G., Tang, C. Y., Farrant, M., and Mody, I. (2003). Neuroactive steroids reduce neuronal excitability by selectively enhancing tonic inhibition mediated by $\delta$ subunit-containing GABAA receptors. Proc. Natl. Acad. Sci. U S A 100, 14439-14444. doi: 10.1073/pnas.2435457100

Stödberg, T., McTague, A., Ruiz, A. J., Hirata, H., Zhen, J., Long, P., et al. (2015). Mutations in SLC12A5 in epilepsy of infancy with migrating focal seizures. Nat. Commun. 6:8038. doi: 10.1038/ncomms9038

Sutula, T., Cascino, G., Cavazos, J., Parada, I., and Ramirez, L. (1989). Mossy fiber synaptic reorganization in the epileptic human temporal lobe. Ann. Neurol. 26, 321-330. doi: 10.1002/ana.410260303

Tauck, D. L., and Nadler, J. V. (1985). Evidence of functional mossy fiber sprouting in hippocampal formation of kainic acid-treated rats. J. Neurosci. 5, 1016-1022.

Tönges, L., Günther, R., Suhr, M., Jansen, J., Balck, A., Saal, K.-A., et al. (2014). Rho kinase inhibition modulates microglia activation and improves survival in a model of amyotrophic lateral sclerosis. Glia 62, 217-232. doi: 10.1002/glia. 22601
Toyoda, I., Bower, M. R., Leyva, F., and Buckmaster, P. S. (2013). Early activation of ventral hippocampus and subiculum during spontaneous seizures in a rat model of temporal lobe epilepsy. J. Neurosci. 33, 11100-11115. doi: 10. 1523/JNEUROSCI.0472-13.2013

Turski, W. A., Cavalheiro, E. A., Schwarz, M., Czuczwar, S. J., Kleinrok, Z., and Turski, L. (1983). Limbic seizures produced by pilocarpine in rats: behavioural, electroencephalographic and neuropathological study. Behav. Brain Res. 9, 315-335. doi: 10.1016/0166-4328(83)90136-5

Valente, S. G., Naffah-Mazzacoratti, M. G., Pereira, M., Silva, I., Santos, N. F., Baracat, E. C., et al. (2002). Castration in female rats modifies the development of the pilocarpine model of epilepsy. Epilepsy Res. 49, 181-188. doi: 10. 1016/s0920-1211(02)00024-4

Volz, F., Bock, H. H., Gierthmuehlen, M., Zentner, J., Haas, C. A., and Freiman, T. M. (2011). Stereologic estimation of hippocampal GluR2/3- and calretininimmunoreactive hilar neurons (presumptive mossy cells) in two mouse models of temporal lobe epilepsy. Epilepsia 52, 1579-1589. doi: 10.1111/j.1528-1167. 2011.03086.x

Winkelmann, A., Semtner, M., and Meier, J. C. (2015). Chloride transporter KCC2-dependent neuroprotection depends on the N-terminal protein domain. Cell Death Dis. 6:e1799. doi: 10.1038/cddis.2015.177

Yamashita, K., Kotani, Y., Nakajima, Y., Shimazawa, M., Yoshimura, S.-I., Nakashima, S., et al. (2007). Fasudil, a Rho kinase (ROCK) inhibitor, protects against ischemic neuronal damage in vitro and in vivo by acting directly on neurons. Brain Res. 1154, 215-224. doi: 10.1016/j.brainres.2007.04.013

Zhou, Y., Su, Y., Li, B., Liu, F., Ryder, J. W., Wu, X., et al. (2003). Nonsteroidal anti-inflammatory drugs can lower amyloidogenic Abeta 42 by inhibiting Rho. Science 302, 1215-1217. doi: 10.1126/science.1090154

Conflict of Interest Statement: The authors declare that the research was conducted in the absence of any commercial or financial relationships that could be construed as a potential conflict of interest.

Copyright (c) 2015 Kourdougli, Varpula, Chazal and Rivera. This is an open-access article distributed under the terms of the Creative Commons Attribution License (CC $B Y)$. The use, distribution and reproduction in other forums is permitted, provided the original author(s) or licensor are credited and that the original publication in this journal is cited, in accordance with accepted academic practice. No use, distribution or reproduction is permitted which does not comply with these terms. 